\title{
Correction: S. Vogelgsang et al. Fusarium Mycotoxins in Swiss Wheat: A Survey of Growers' Samples between 2007 and 2014 Shows Strong Year and Minor Geographic Effects. Toxins 2017, 9, 246
}

\author{
Susanne Vogelgsang ${ }^{1, *}$ (i) , Tomke Musa ${ }^{1}$, Irene Bänziger ${ }^{1}$, Andreas Kägi ${ }^{1}$, \\ Thomas D. Bucheli ${ }^{1}$, Felix E. Wettstein ${ }^{1}$, Matias Pasquali ${ }^{2}$ and Hans-Rudolf Forrer ${ }^{1}$ \\ 1 Agroscope, Reckenholzstrasse 191, 8046 Zurich, Switzerland; tomke.musa@agroscope.admin.ch (T.M.); \\ irene.baenziger@agroscope.admin.ch (I.B.); andreas.kaegi@agroscope.admin.ch (A.K.); \\ thomas.bucheli@agroscope.admin.ch (T.D.B.); felix.wettstein@agroscope.admin.ch (F.E.W.); \\ hans-rudolf.forrer@agroscope.admin.ch (H.-R.F.) \\ 2 Department of Food, Environmental and Nutritional Sciences, University of Milan, Via Mangiagalli 25, \\ 20133 Milano, Italy; matias.pasquali@unimi.it \\ * Correspondence: susanne.vogelgsang@agroscope.admin.ch; Tel.: +41-58-468-7229
}

Academic Editor: Sarah De Saeger

Received: 9 November 2017; Accepted: 19 November 2017; Published: 21 November 2017

The authors wish to correct Figures 3-5 in this paper [1]. In all three figures, the y axis stated as a unit "milligram $/ \mathrm{kg}$ " $(\mathrm{mg} / \mathrm{kg})$ instead of "microgram $/ \mathrm{kg}$ " $(\mu \mathrm{gg} / \mathrm{kg})$.

Replace

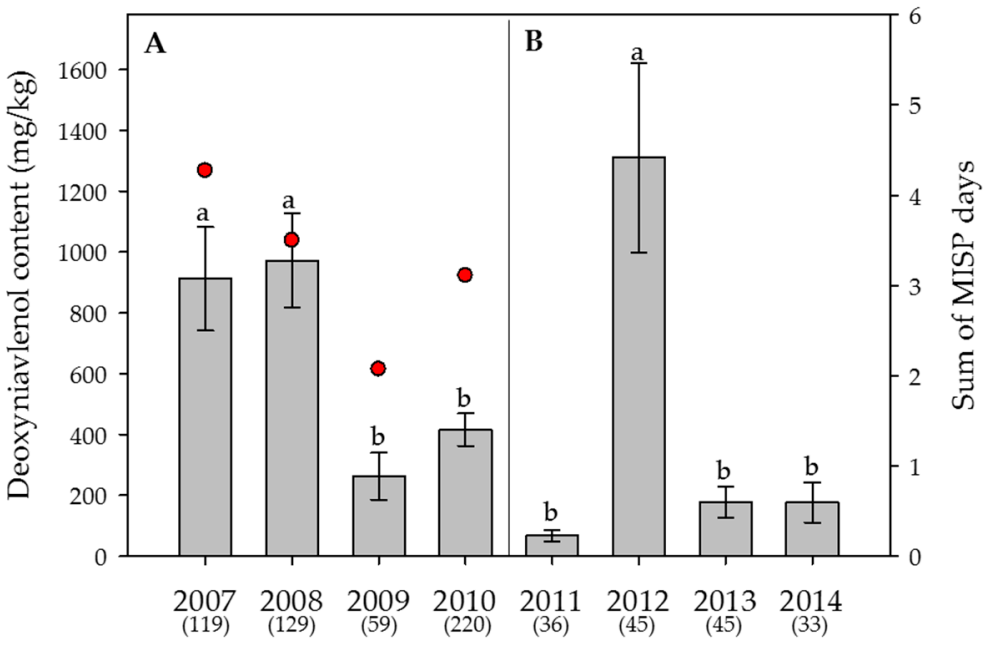

Figure 3. Effect of the year on the average content of deoxynivalenol in wheat. (A) Swiss-wide monitoring (2007-2010); (B) monitoring in the canton Berne (2011-2014). Numbers in parentheses indicate the number of samples. Error bars represent the standard error of the means. For each monitoring set, values followed by the same letters are not statistically different $(\alpha=0.05)$. The red circles in (A) indicate the sum of the "Main Infection and Sporulation Period" (MISP) days (days with a high infection risk by Fusarium graminearum), averaged over 17 weather stations, calculated by the Swiss forecasting system FusaProg for the periods of anthesis for the years 2007 to 2010 . No MISP calculations were done for the monitoring between 2011 and 2014 .

with 


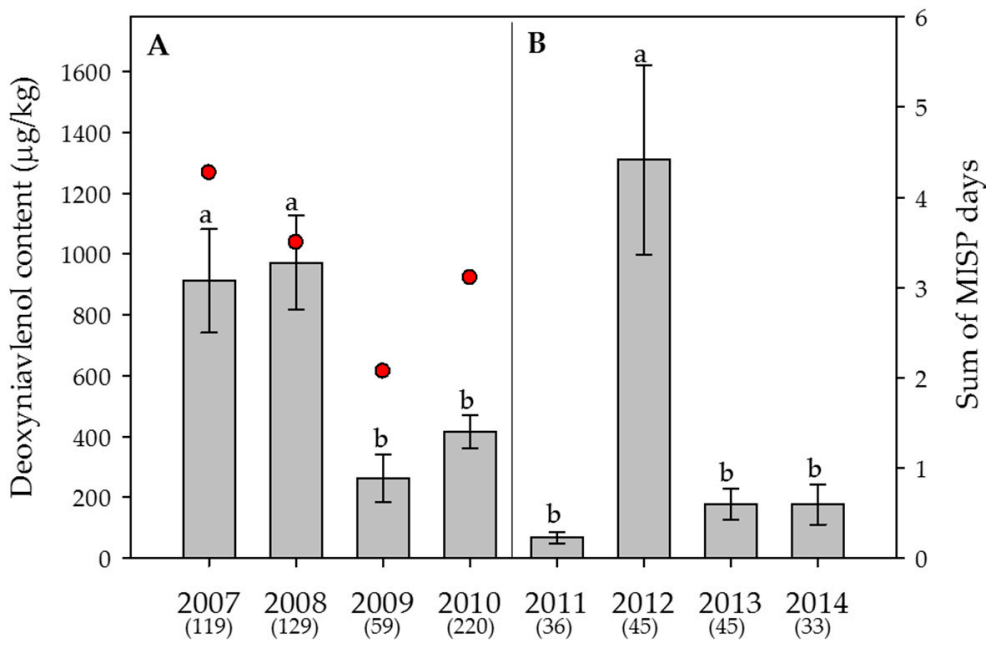

Figure 3. Effect of the year on the average content of deoxynivalenol in wheat. (A) Swiss-wide monitoring (2007-2010); (B) monitoring in the canton Berne (2011-2014). Numbers in parentheses indicate the number of samples. Error bars represent the standard error of the means. For each monitoring set, values followed by the same letters are not statistically different $(\alpha=0.05)$. The red circles in (A) indicate the sum of the "Main Infection and Sporulation Period" (MISP) days (days with a high infection risk by Fusarium graminearum), averaged over 17 weather stations, calculated by the Swiss forecasting system FusaProg for the periods of anthesis for the years 2007 to 2010 . No MISP calculations were done for the monitoring between 2011 and 2014.

Replace

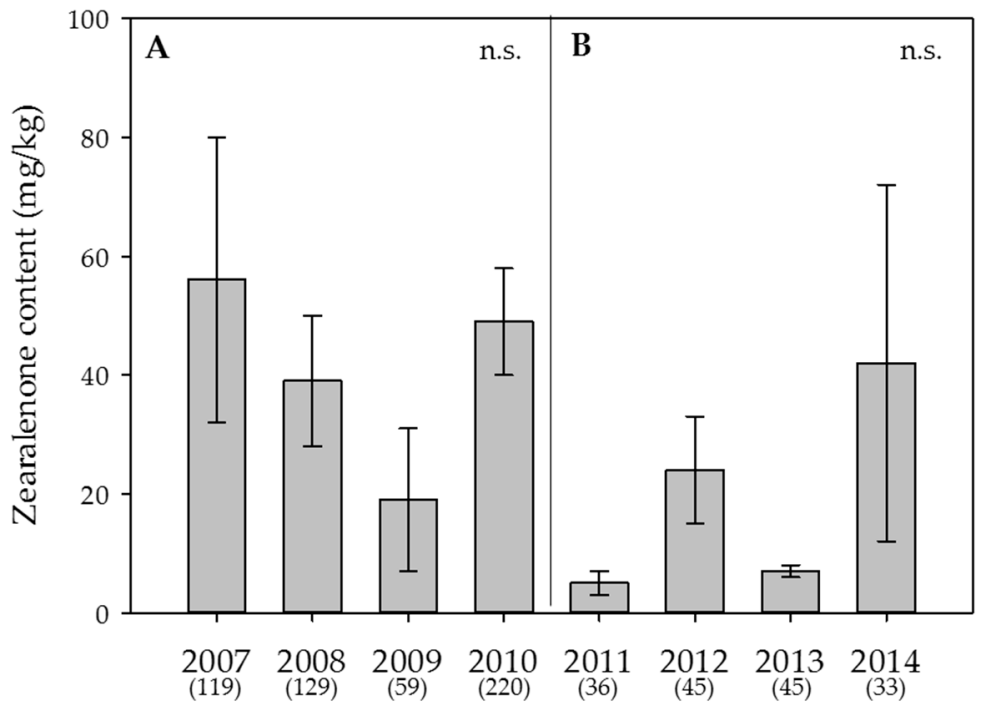

Figure 4. Effect of the year on the average content of zearalenone in wheat. (A) Swiss-wide monitoring (2007-2010); (B) monitoring in the canton Berne (2011-2014). Numbers in parentheses indicate the number of samples. Error bars represent the standard error of the means. n.s. $=$ not significant $(\alpha=0.05)$.

with 


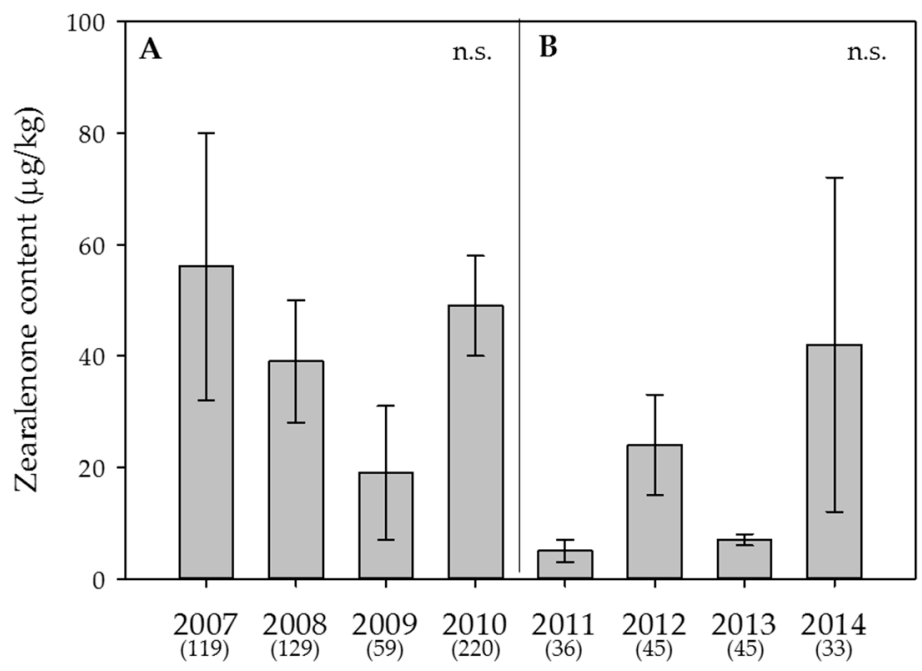

Figure 4. Effect of the year on the average content of zearalenone in wheat. (A) Swiss-wide monitoring (2007-2010); (B) monitoring in the canton Berne (2011-2014). Numbers in parentheses indicate the number of samples. Error bars represent the standard error of the means. n.s. $=$ not significant $(\alpha=0.05)$.

Replace

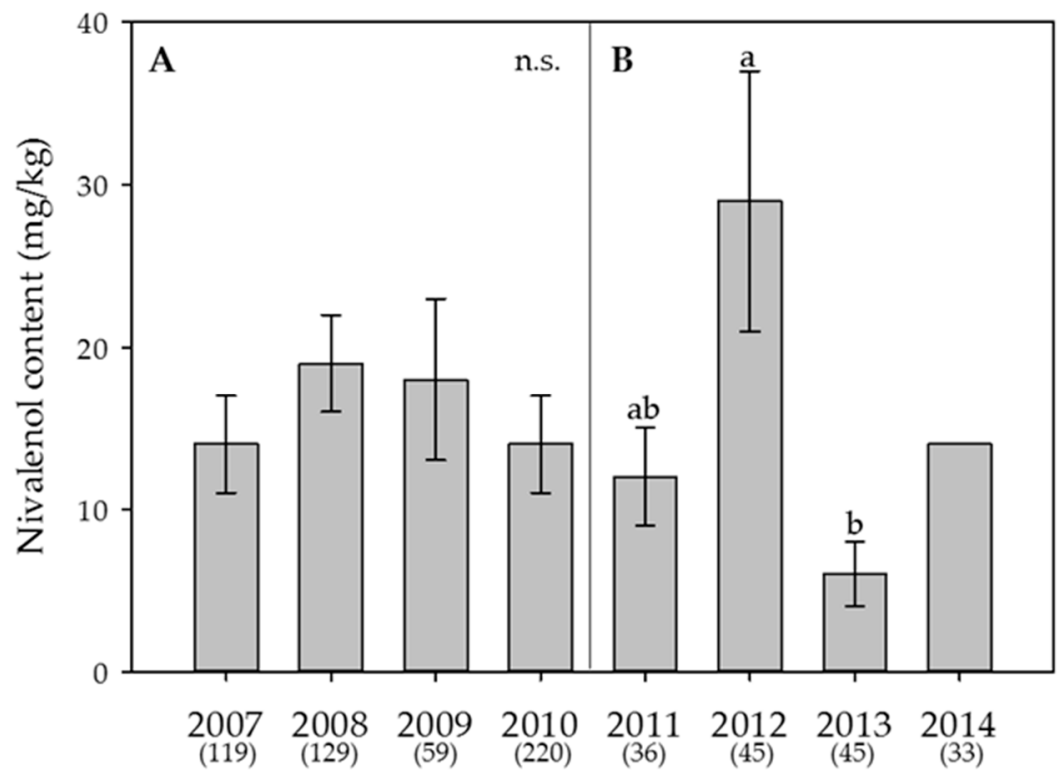

Figure 5. Effect of the year on the average content of nivalenol in wheat. (A) Swiss-wide monitoring (2007-2010); (B) monitoring in the canton Berne (2011-2014). For 2014, no statistical analyses were performed since the content in that year was always below the limit of detection. Numbers in parentheses indicate the number of samples. Error bars represent the standard error of the means. For each monitoring set, values followed by the same letters are not statistically different $(\alpha=0.05)$; n.s. $=$ not significant $(\alpha=0.05)$.

with 


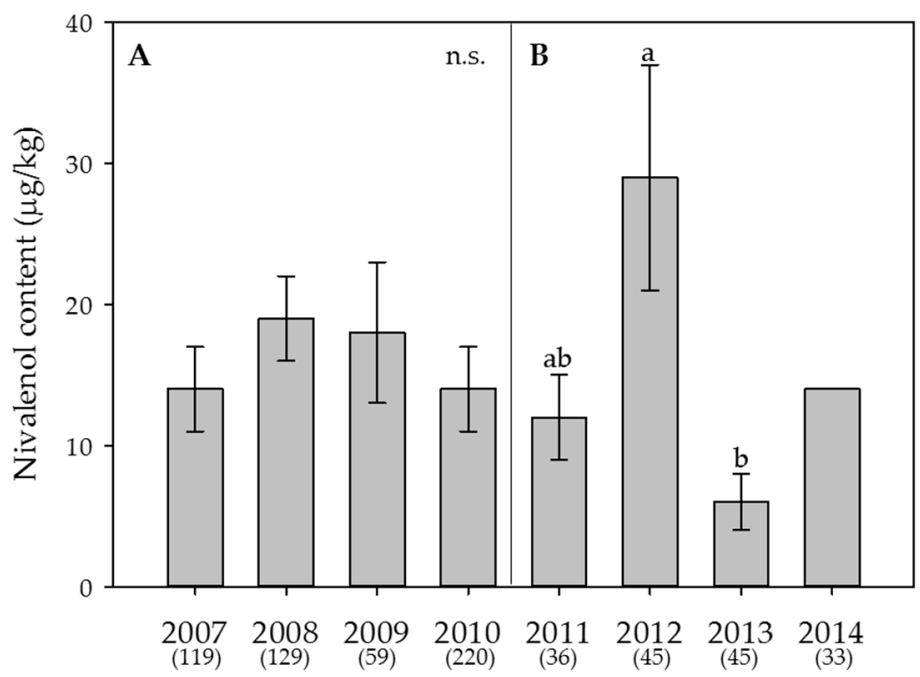

Figure 5. Effect of the year on the average content of nivalenol in wheat. (A) Swiss-wide monitoring (2007-2010); (B) monitoring in the canton Berne (2011-2014). For 2014, no statistical analyses were performed since the content in that year was always below the limit of detection. Numbers in parentheses indicate the number of samples. Error bars represent the standard error of the means. For each monitoring set, values followed by the same letters are not statistically different $(\alpha=0.05)$; n.s. $=$ not significant $(\alpha=0.05)$.

The changes do not affect the scientific results. The manuscript will be updated and the original will remain online on the article webpage. We apologize for any inconvenience caused to our readers.

\section{Reference}

1. Vogelgsang, S.; Musa, T.; Bänziger, I.; Kägi, A.; Bucheli, T.D.; Wettstein, F.E.; Forrer, H.R. Fusarium Mycotoxins in Swiss Wheat: A Survey of Growers' Samples between 2007 and 2014 Shows Strong Year and Minor Geographic Effects. Toxins 2017, 9, 246. [CrossRef] [PubMed]

(C) 2017 by the authors. Licensee MDPI, Basel, Switzerland. This article is an open access article distributed under the terms and conditions of the Creative Commons Attribution (CC BY) license (http:/ / creativecommons.org/licenses/by/4.0/). 